This item was submitted to Loughborough's Research Repository by the author.

Items in Figshare are protected by copyright, with all rights reserved, unless otherwise indicated.

\title{
Effect of infra-red power level on the sintering behaviour in the high speed sintering process
}

PLEASE CITE THE PUBLISHED VERSION

PUBLISHER

(C) Emerald Group Publishing Limited

LICENCE

CC BY-NC-ND 4.0

REPOSITORY RECORD

Majewski, Candice E., D. Oduye, H.R. Thomas, and Neil Hopkinson. 2019. "Effect of Infra-red Power Level on the Sintering Behaviour in the High Speed Sintering Process". figshare. https://hdl.handle.net/2134/3493. 
This item was submitted to Loughborough's Institutional Repository by the author and is made available under the following Creative Commons Licence conditions.

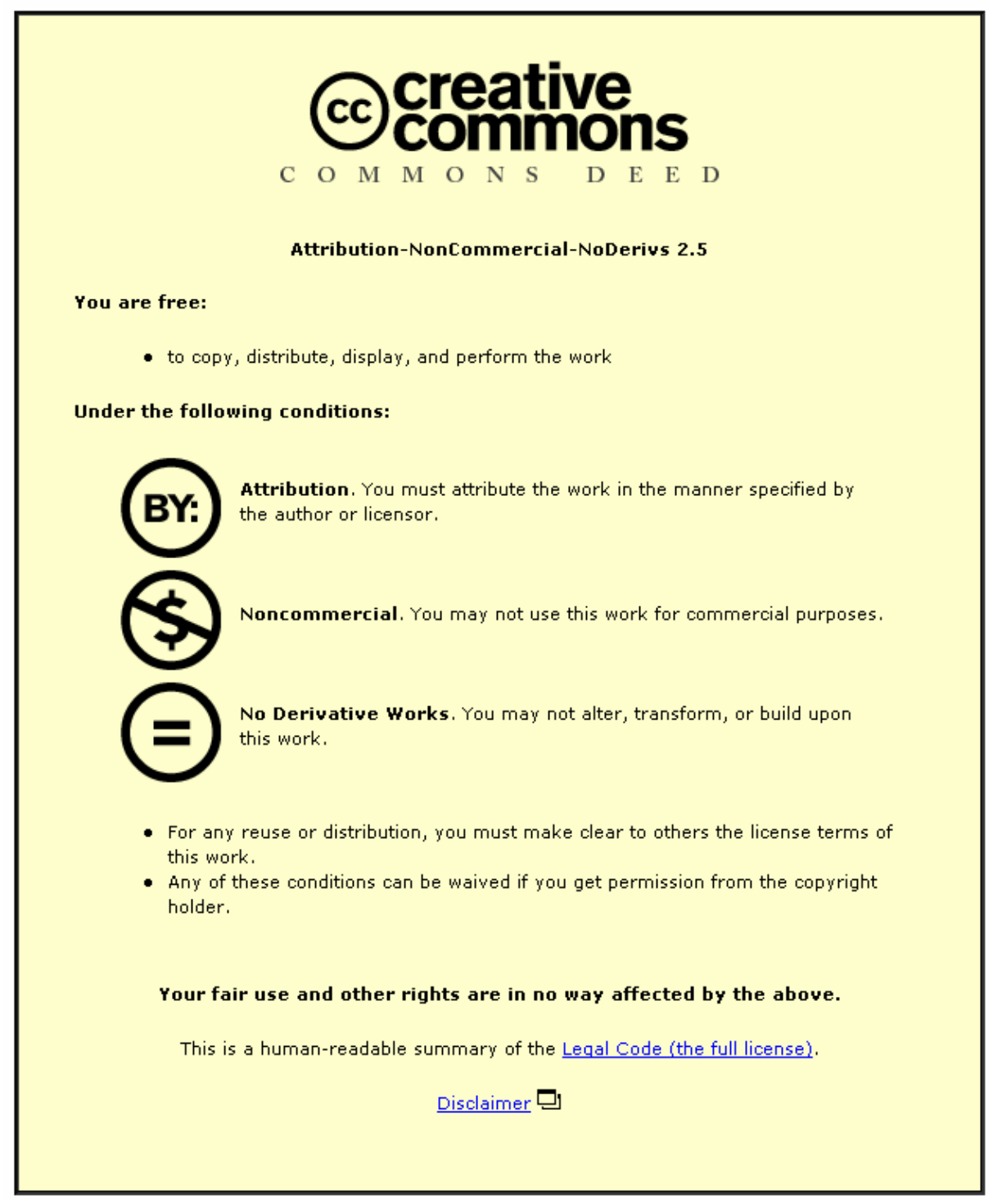

For the full text of this licence, please go to: http://creativecommons.org/licenses/by-nc-nd/2.5/ 
Effect of infra-red power level on the sintering behaviour in the High Speed Sintering process

\author{
C.E.Majewski, D.Oduye, H.R.Thomas, N.Hopkinson
}

\title{
Abstract
}

Purpose: To investigate the effects of the infra-red power level on sintering behaviour in the High Speed Sintering process.

Design/methodologylapproach: Single-layer parts were produced using the High Speed Sintering process, in order to determine the effect of the infra-red power level on the maximum achievable layer thickness, and the degree of sintering. The parts were examined using both optical microscopy and contact methods.

Findings: Whilst it was expected that an increase in the infra-red lamp powder might allow an increase in the depth of sintering that could be achieved, as a result of increased thermal transfer through the powder, results in fact indicated that there is a maximum layer thickness that can be achieved, as a result of part shrinkage in the $z$ direction.

Optical microscopy images have shown that a greater degree of sintering occurs at higher power levels, which would be expected to correspond to an improvement in the mechanical properties of the parts produced. These images also indicate that the RAM forms in small 'islands' on the powder bed surface. However, these islands begin to merge as sintering progresses, to a greater degree as the infra-red lamp power is increased.

Research limitations/implications: These results are based only on single layer parts. Further work will examine the sintering characteristics of multiple layer parts.

Practical implications: Results have shown that, whilst it is not possible to increase the achievable layer thickness of the parts produced by modifying the infra-red lamp power, the degree of sintering can be improved greatly by increasing the power.

Originality/value: High Speed Sintering is an entirely new process which is currently still under development; the results presented here will directly impact the direction of further development and research into this process.

Keywords: Rapid Prototyping, Rapid Manufacturing, High Speed Sintering, layer thickness, part shrinkage

\section{Introduction}

\section{$1.1 \quad$ Rapid Manufacturing}


Rapid prototyping (RP) is a family of technologies that has developed since the late 1980's whereby solid objects are manufactured in a layer by layer approach $^{1}$. All RP processes require a solid CAD model of a part to be created that is then split into discrete slices the thickness of which is dependent upon the process and parameters to be used to make the final part. Rapid prototyping has had a major impact on manufacturing to date by allowing companies to improve their product development projects by enabling quick and easy production of prototypes ${ }^{2}$. Recently parts made on RP machines have been used as end use products rather than as prototypes - this has led to the term Rapid Manufacturing (RM) ${ }^{3}$.

RM examples to date include the manufacture of bespoke hearing aids ${ }^{3}$, bespoke foot ball boots ${ }^{4}$ and ducts for military aircraft ${ }^{5}$. All of these applications employ Selective Laser Sintering (SLS) of polymers, the process that dominates RM today. Additionally these examples all involve the manufacture of one-off or low volume series parts. For higher production volumes the time taken to make parts, along with high costs of machines and materials, makes RM unlikely to be commercially viable, especially for large parts with simple geometries ${ }^{6}$. In order to address the issue of machine cost and speed a number of processes have been developed to make parts that have the properties of SLS using a much quicker build time and lower cost machine. These processes include the Speedpart process ${ }^{1}$, Selective Inhibition Sintering ${ }^{7,8}$, Electrophotographic Layer Manufacturing ${ }^{9,10}$ and High Speed Sintering ${ }^{11}$, all of which sinter powders in a layer by layer manner without the use of a laser.

\subsection{High Speed Sintering process}

High Speed Sintering is a new, powder-based, layer manufacturing process, developed at Loughborough University ${ }^{11,12}$. The process has similarities with Selective Laser Sintering (SLS), in that it sinters the required cross-sectional area of subsequent layers of powder in order to create the final part. At present the machine used is a modified DTM Sinterstation $2500 \mathrm{Cl}$, and the powder used is Duraform PA (Nylon 12).

The major difference between SLS and HSS is in the mechanism by which sintering is initiated. Whereas the SLS process uses a laser to sinter the cross-sectional profile, the HSS process deposits a Radiation Absorbing Material (RAM) over the appropriate area and an infra-red lamp (Philips 15005Z) is then flashed across the entire build area (see Figure 1). 


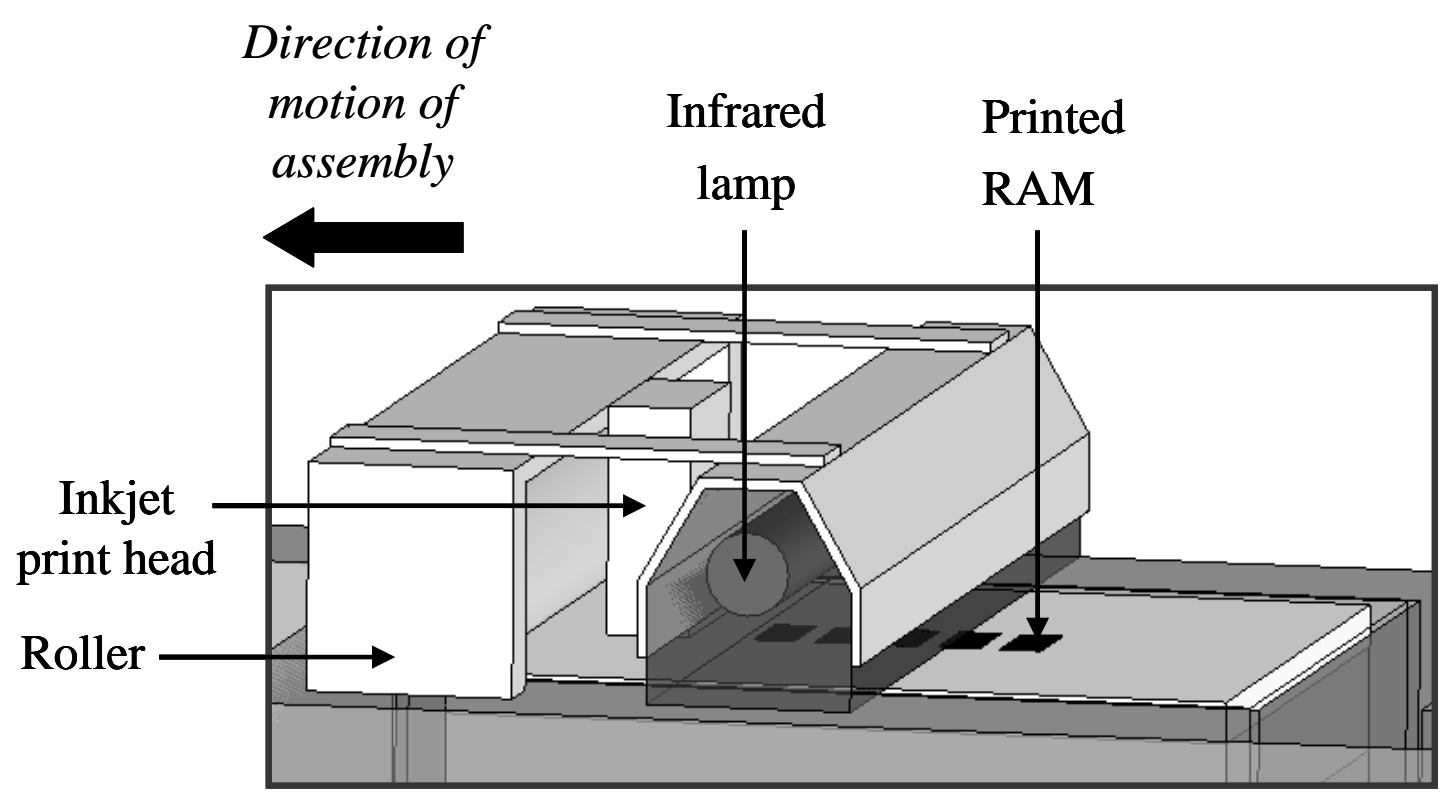

Figure 1 - HSS machine set-up

Given the selection of an appropriate RAM for the powder used, areas in which the powder is printed by the RAM will absorb sufficient energy to elevate the temperature of the powder to its melt point, allowing sintering to take place. Areas not printed with the RAM will absorb less energy, therefore not exceeding their melt point and not becoming sintered. The un-sintered powder can be brushed away from the part upon completion of the build.

The process also has similarities with 3 Dimensional Printing (3DP), as the RAM is deposited onto the powder via a standard inkjet print head, providing high resolution and high speed deposition.

Figure 2 demonstrates the major areas of similarity between High Speed Sintering and the SLS and 3DP processes.

\section{Selective Laser Sintering}

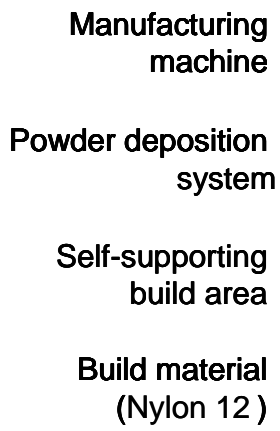

\section{D Printing}

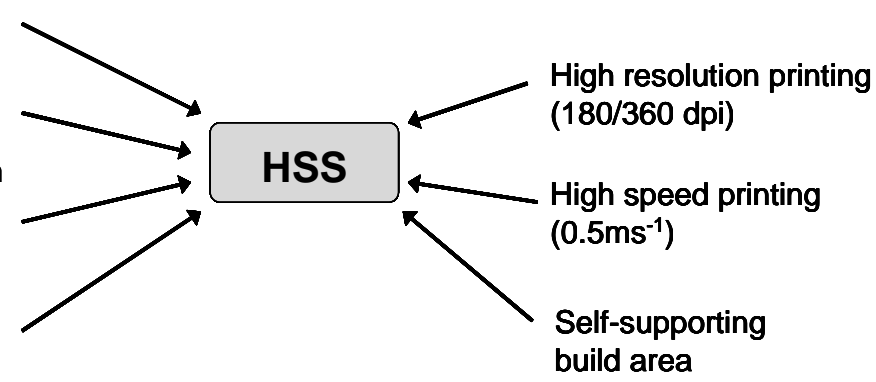

Figure 2 - Similarities between HSS, SLS and 3DP

The HSS process can be broken down into several discrete steps, as detailed below: 
1. Production of CAD model - standard CAD software can be used to produce the CAD model of a part, as with other RP\&M processes

2. Slicing - The CAD model is then sliced into discrete cross-sections and transferred to the HSS machine

3. Pre-heating - The powder bed and feed chambers are pre-heated to levels below the melt temperature of the powder material

4. Powder deposition - Powder is deposited via a roller system onto the build area

5. Printing - The RAM is deposited over the required cross-sectional area via the inkjet print head

6. IR exposure - Following the printing of the area, an infra-red lamp is flashed over the entire build area, sintering the areas of powder on which the RAM has been deposited

[4. Powder deposition - A subsequent layer of powder is deposited onto the build area, and the process is repeated]

7. Cool down - The machine is left to cool before part removal

8. Powder removal - Unsintered powder is removed from the parts

Figure 3 demonstrates the HSS process chain.

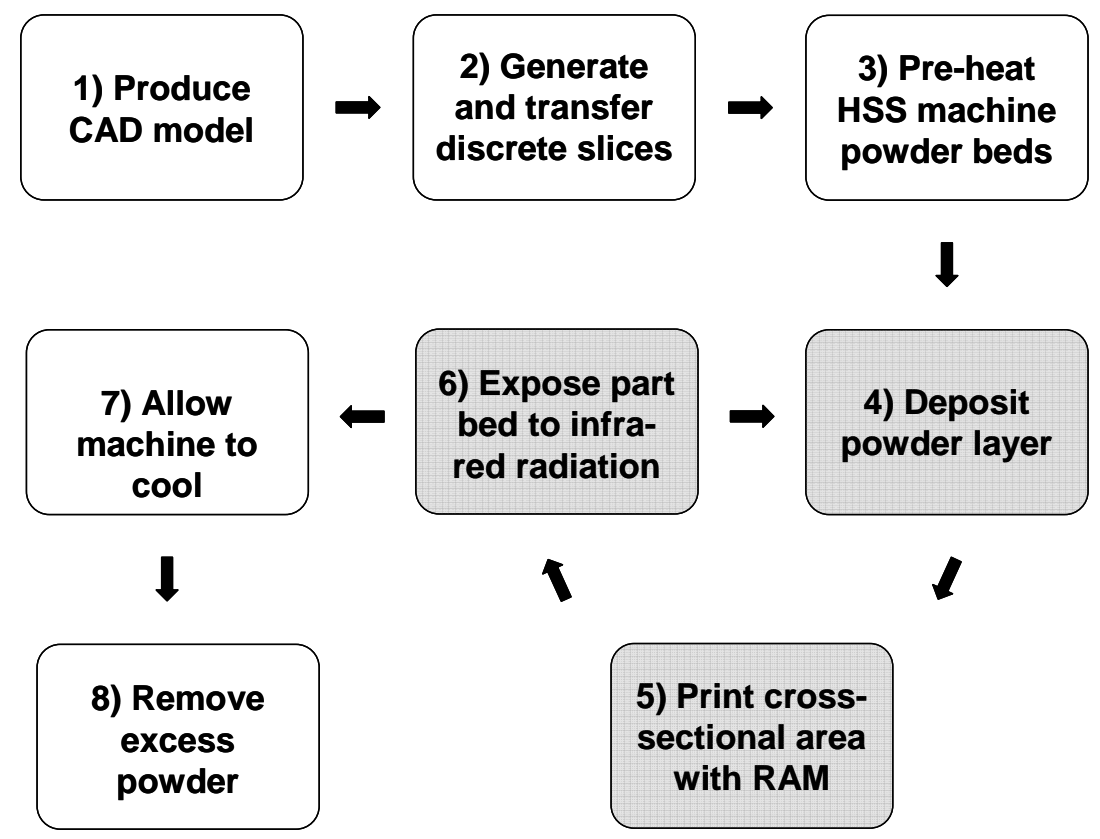

Figure 3 - High Speed Sintering process chain

\subsection{Benefits of HSS}

The HSS process allows for much higher build speeds than, for example, SLS, as a result of sintering much larger areas simultaneously rather than using the time-consuming approach of scanning the cross-section with a laser. The method of sintering also means that the build time per layer is constant, irrespective of the size, amount and shape of the 2D profiles in each layer. This will have particularly important repercussions when using HSS as a Rapid Manufacturing process. The lack of requirement for a laser system and optics will also reduce the cost of the machine itself. 
As with both SLS and 3DP, the process has a self-supporting build area, using both the sintered and unsintered powder below the current layer in order to provide support for the cross-section in progress.

The use of inkjet technology allows the production of high resolution parts, without sacrificing the cycle time benefits discussed previously.

\section{Problem definition}

The use of a RAM enhances transfer of heat to the loose powder, allowing the sintering of powder in printed areas. However, no previous work has been carried out to investigate the depth of sintering, and therefore the layer thickness, that can be achieved. It was anticipated that an increase in the IR lamp power would lead to an increase in the possible depth of sintering, and that areas of uniform cross-section could be printed in thicker layers by using a higher lamp power, thereby further increasing the speed of production.

It was also proposed that a greater degree of sintering would be achieved at the higher lamp powers, which would allow the production of stronger parts, with improved mechanical properties.

The research discussed in this paper covered two main areas, as described here:

- The use of optical and contact methods to measure the thickness of a single sintered layer at different lamp powers, in order to determine the effect of increasing the lamp power on the maximum layer thickness which can be achieved.

- Use of optical microscopy to examine the sintering behaviour of parts produced at these different powers.

\section{Experimental work}

\subsection{Part production}

In order to determine the depth of penetration which could be achieved at each power setting, a series of single-layered parts was made at IR lamp setting between 5.0 and 7.5 , the range for which it was known that parts could be produced.

Five circular parts, with a nominal diameter of $30 \mathrm{~mm}$, were produced at each power setting in order that an average value of layer thickness could be obtained for each. Figure 4 shows the whole powder bed, and the positions of the test samples produced. 


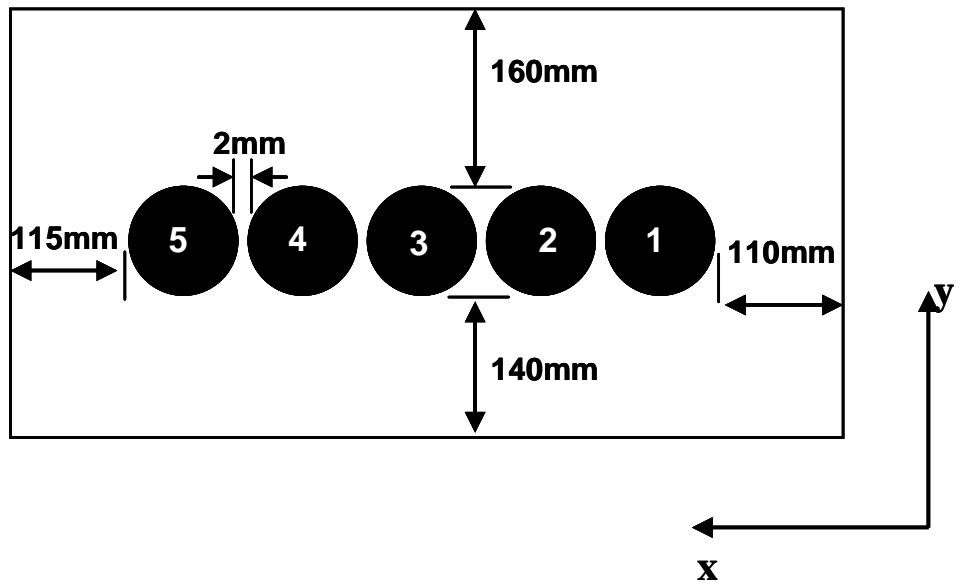

Figure 4 - Build position of test samples

To maintain consistency, the main part bed heater was maintained at a setting of $108^{\circ} \mathrm{C}$ throughout the builds, and the print head settings were not changed during the experiments.

\subsection{Power level calculations}

The current set-up of the machine relies on an simple dial, ranging from 1-10, in order to set the power level for the infra-red lamp. As mentioned previously, it is known that acceptable parts can be produced between lamp settings of 5.0 and 7.5. In order to provide a quantitative value for the lamp power, the power drawn by the lamp at each setting within this range, was measured using a Tenma Digital TRMS Clamp Ammeter.

Figure 5 shows the input power measured at each dial setting.

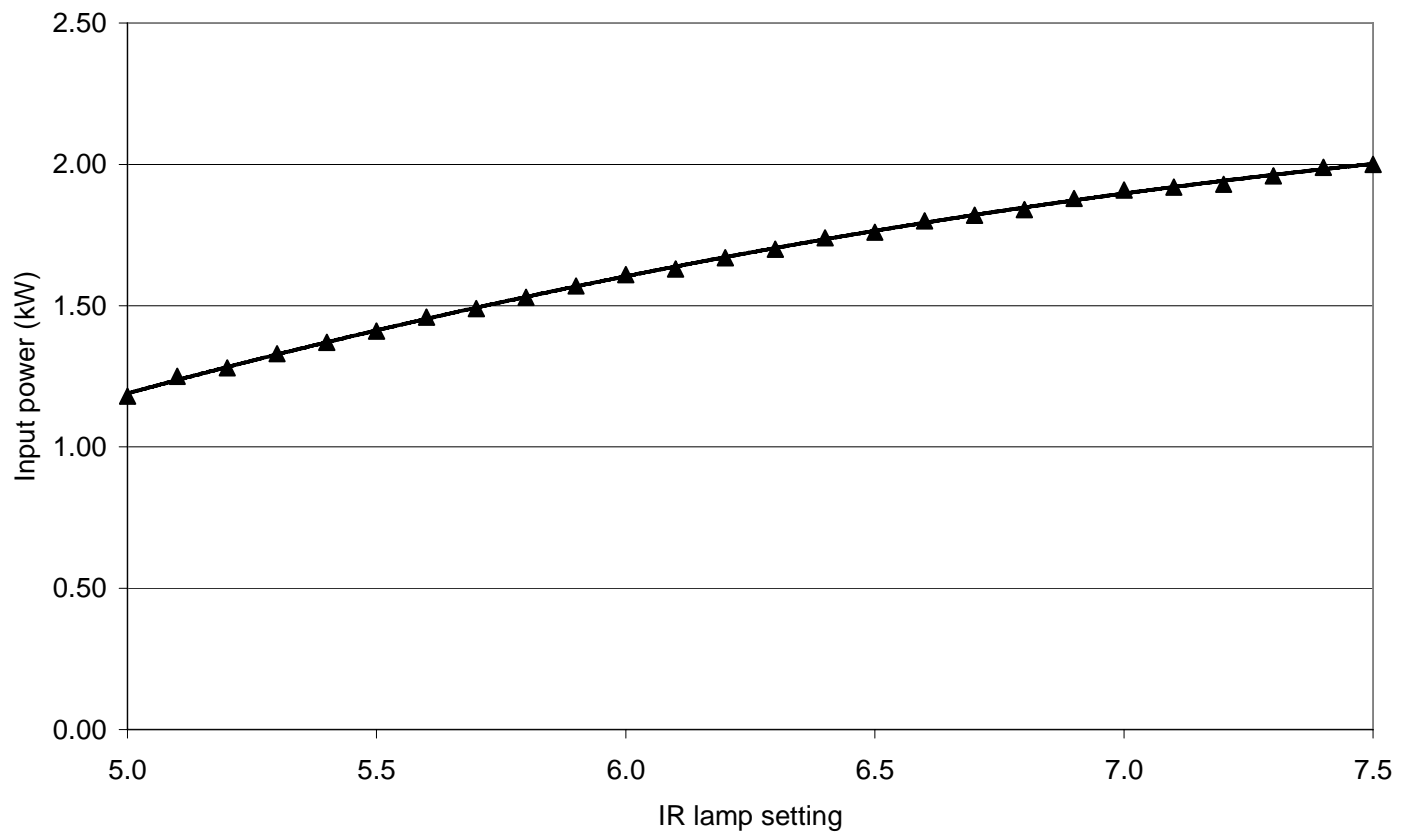

Figure 5 - Correlation between IR lamp setting and input power to lamp 


\section{$4 \quad$ Experimental results - layer thickness}

\subsection{Optical microscopy}

In order to prepare the samples for testing, a portion of each single layer part was carefully cleaned. The sample was clamped between two microscope slides, leaving an area of the part exposed. A light brush was used to remove any excess powder from the sample, after which a manually operated air blower was used to clear any remaining residue. Figure 6 shows the apparatus used.

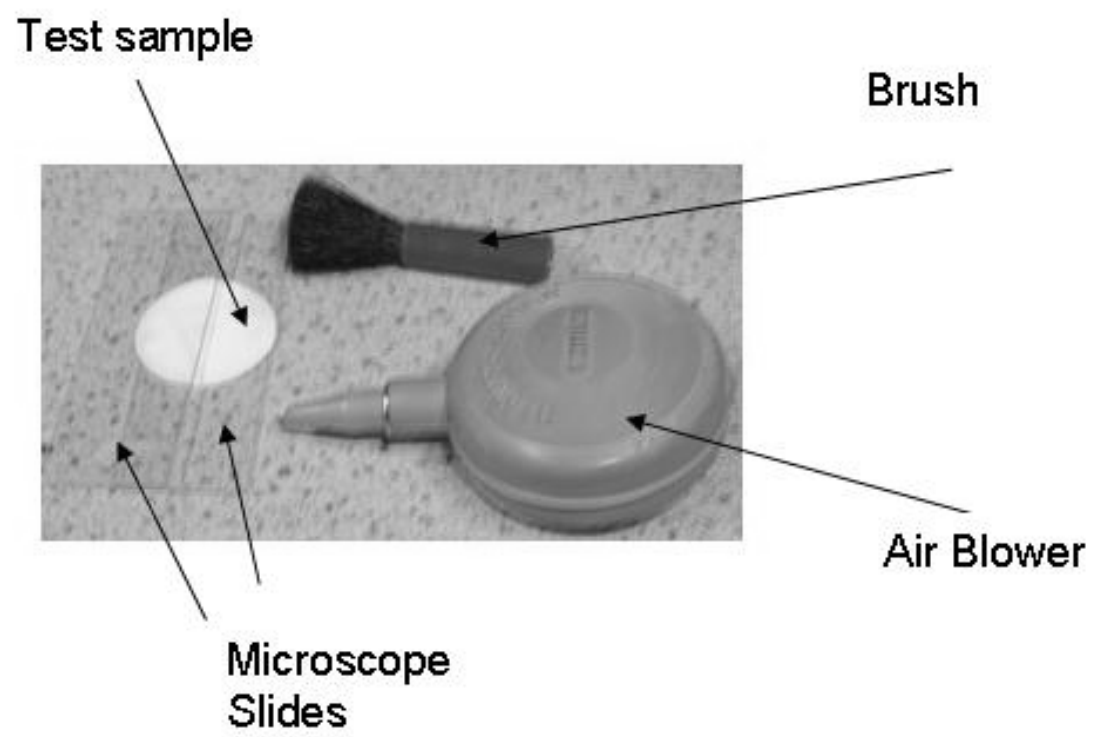

Figure 6 - Cleaning equipment

This method of preparation left a clean area which would be used for the optical layer thickness testing (see Figure 7).

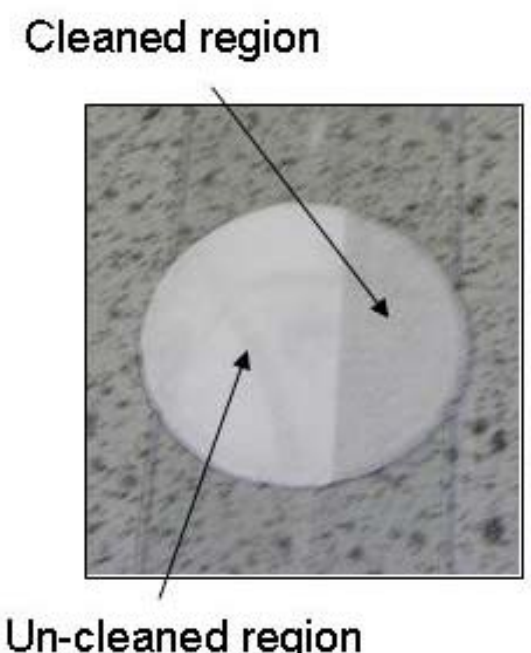

Figure 7 - Cleaned and un-cleaned areas of the sample 
In order to measure the thickness of the sample using optical methods, a straight edge was required on the part. The samples were therefore repeatedly stressed along a straight edge within the clean region of the part until they fractured, thereby reducing the chances of part compression which could be encountered if the samples were simply cut along the straight edge.

A Nikon Optiphot optical microscope was used to capture images of the test samples, which were clamped in place to provide a vertical viewing direction. Figure 8 shows the positioning of the samples.

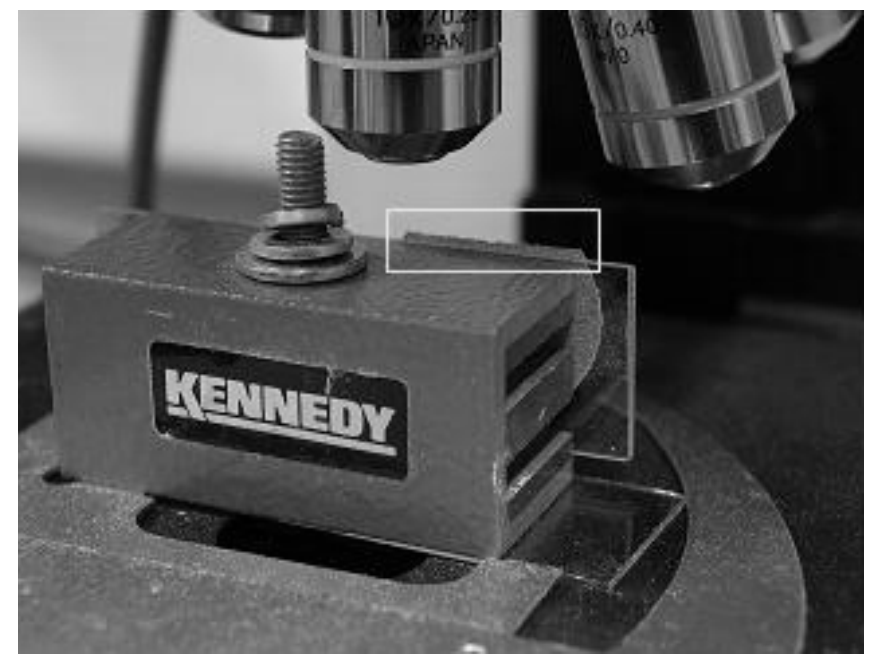

Figure 8 - Sample positioning

An image was taken of each sample, and horizontal guidelines were placed using the IQ115 Image Quantifier software from Cortex Controllers Ltd at the top and bottom of the test sample. The depth of the part was then calculated by the software. However the positioning of the horizontal guidelines required a largely subjective approach, and it can be seen from Figure 9 that the nature of the surfaces were not smooth and flat, but rather showed a large number of peaks and troughs, making this a particularly inaccurate process.

Figure 9 shows a sample image of a single-layer part produced at power level 5.1 . 


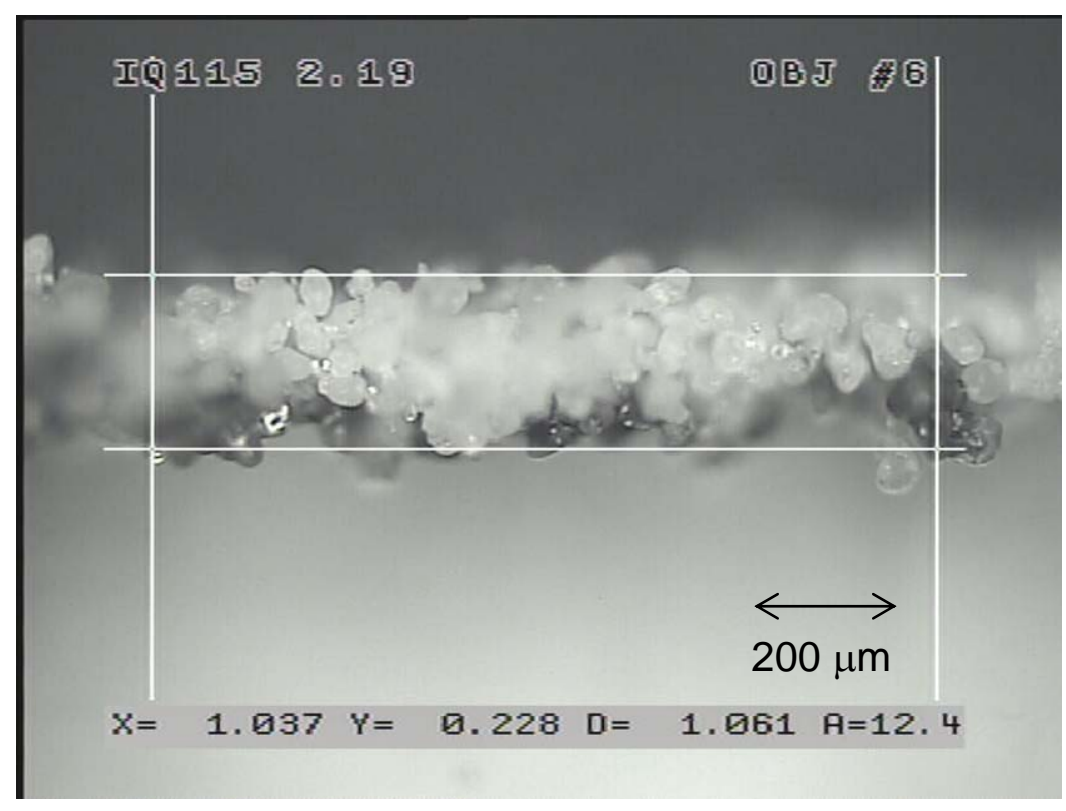

Figure 9 - Optical microscope view of single layer part

Figure 10 shows the maximum, minimum and mean penetration depth of the cleaned sections achieved for the set of 5 samples produced at each power level.

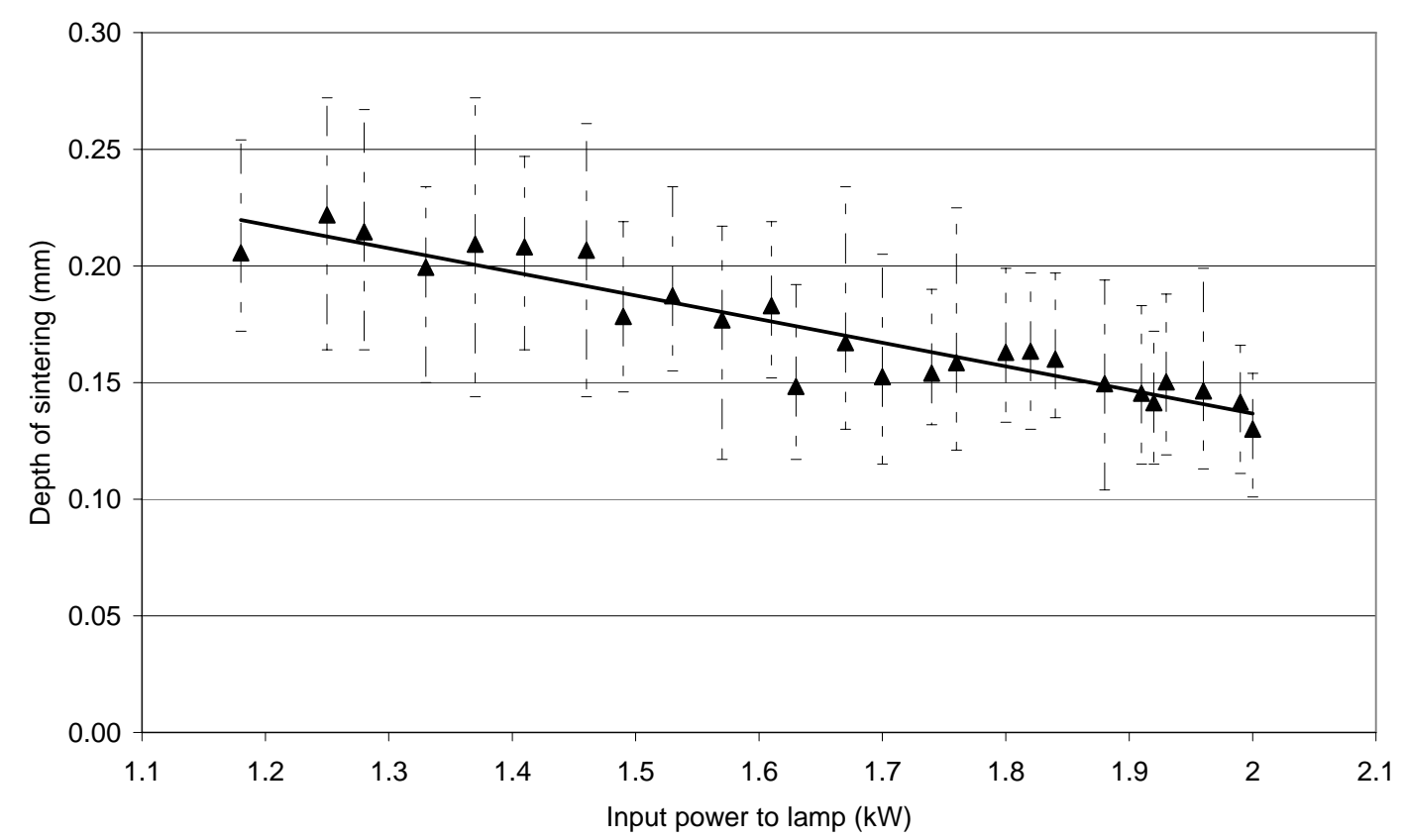

Figure 10 - Optical microscopy measurements of sintering depth of cleaned sections at each power level

It can be seen from Figure 10 that there appears to be a downward trend between the penetration depths obtained at the low power levels and those at the higher power levels. However, the spread of results obtained using the optical microscopy method, and the subjectivity of the method of obtaining the penetration depth, meant that the results obtained did not provide a satisfactory level of confidence. It was therefore decided to perform further measurements using contact, rather than optical, methods. 


\section{Contact measurements}

In order to provide greater accuracy than that which was achieved using the optical methods, a micrometer was used to measure the thickness of each single layer part. Initial measurements were taken on each sample in an area which had not been cleaned.

Figure 11 shows the values obtained for the average thickness at each power level, for the un-cleaned sections of the test samples.

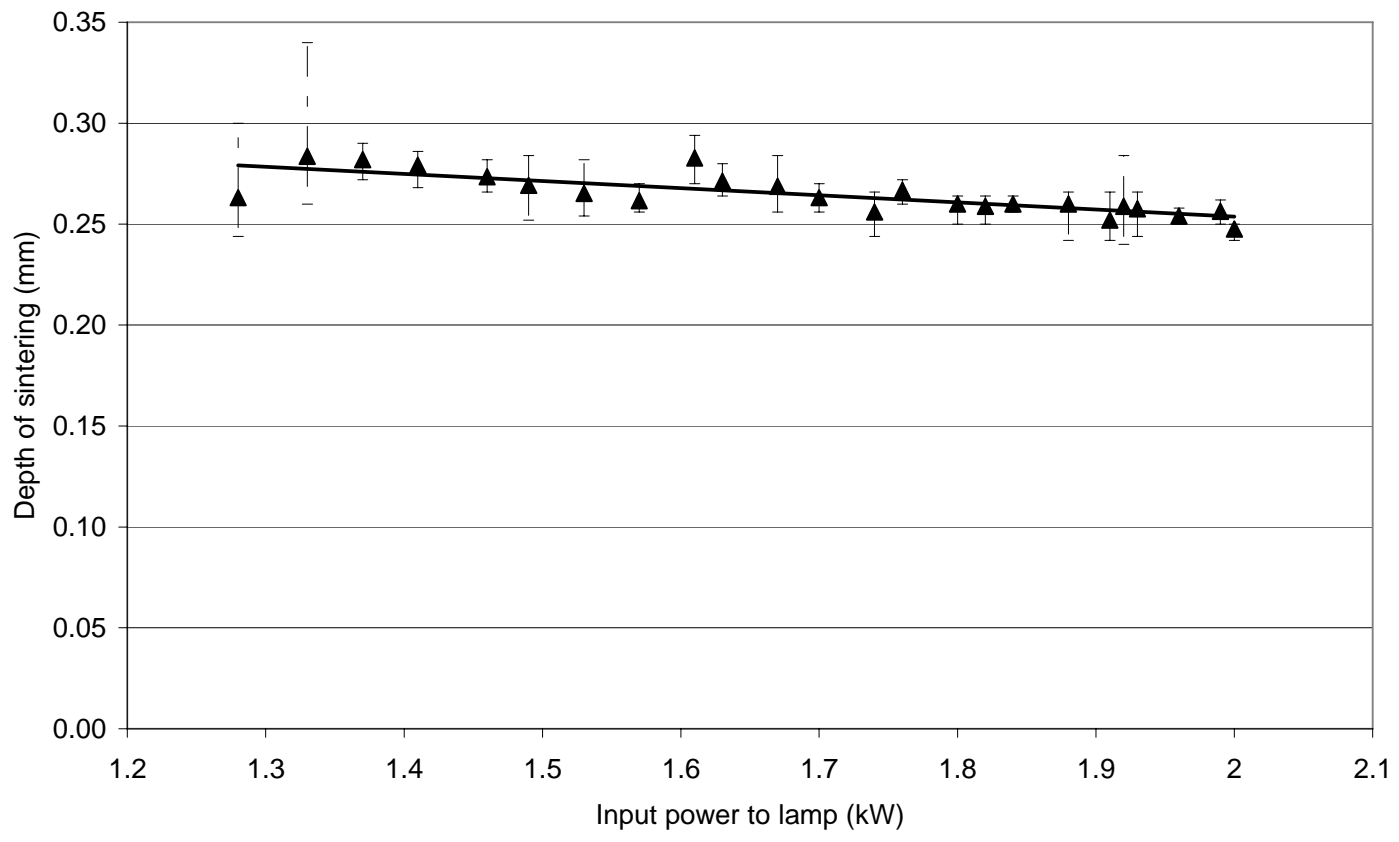

Figure 11 - Micrometer measurements of sintering depth at each power level (un-cleaned)

It can immediately be seen that the spread of results at each power level was much less than for the results obtained using optical microscopy, with a maximum range of $0.08 \mathrm{~mm}$ as compared with $0.128 \mathrm{~mm}$, giving substantially greater confidence in the accuracy of the observed trend. The results again indicated a slight decrease (approximately $0.036 \mathrm{~mm}$ ) in the layer thickness produced at the highest power setting than at the lower levels.

In order to identify the influence of part cleaning on the perceived layer thickness, each sample was tested once again, this time on the section which was cleaned prior to the optical microscopy testing. Figure 12 shows the results of these measurements. 


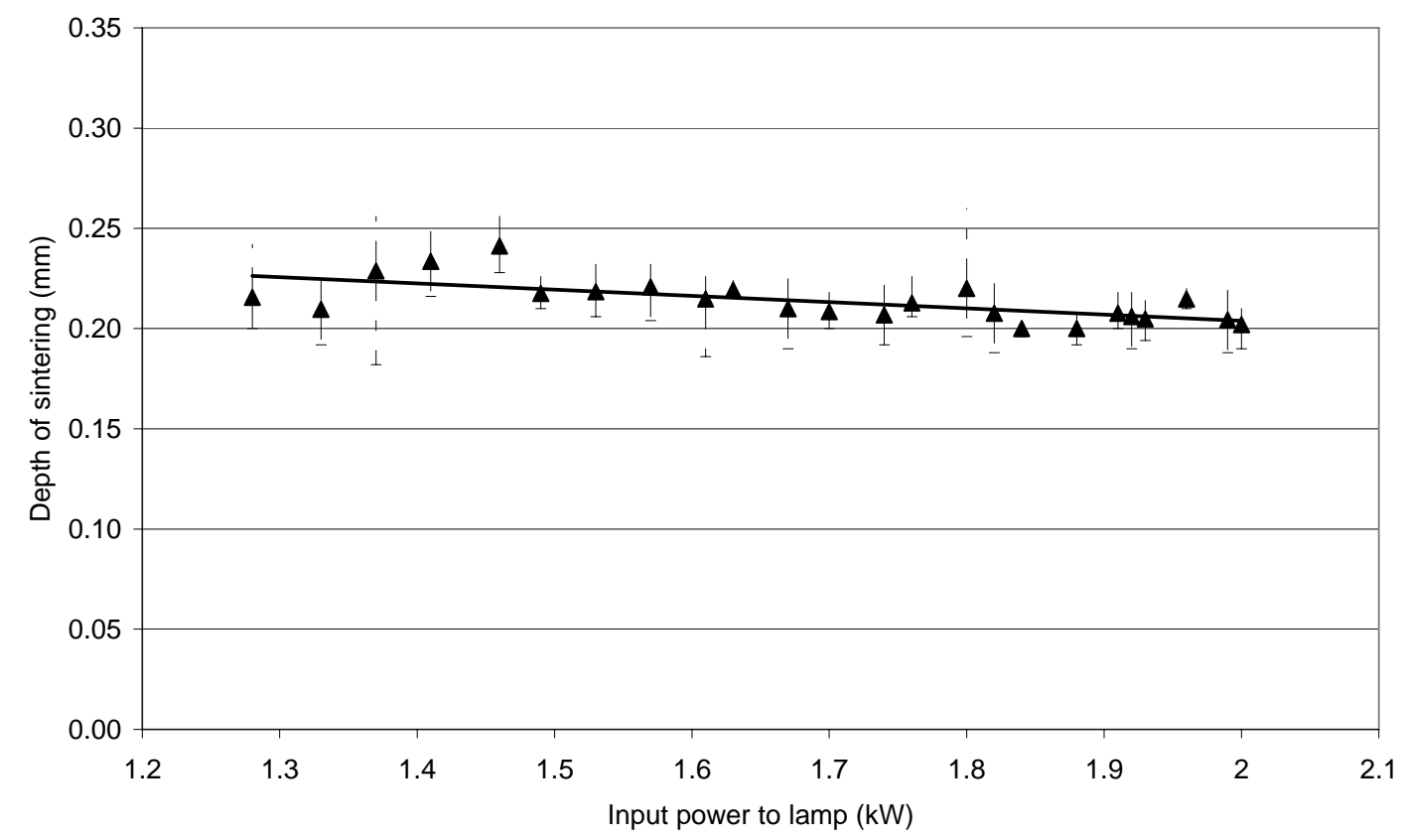

Figure 12 - Micrometer measurements of sintering depth at each power level (cleaned)

It can again be seen that an almost identical downwards trend was observed once more, with the decrease in layer thickness between the lowest and highest power levels measured as $0.041 \mathrm{~mm}$. However, in this case the average values measured for each power level were approximately $0.05 \mathrm{~mm}$ lower than those recorded on the un-cleaned parts. The maximum range of values recorded at any input power was, in this case, only $0.074 \mathrm{~mm}$.

\section{Discussion of layer thickness results}

\section{Effect of part cleaning}

It was seen that, prior to cleaning of the samples, there was a fine layer (approximately $0.05 \mathrm{~mm}$ ) of powder remaining on the underside of each part, corresponding to the just under the average thickness of a single polymer particle (nominally $0.058 \mathrm{~mm}$ ). After gentle cleaning was applied, this layer of powder was removed. These results provide some evidence of a very minor degree of sintering of single polymer particles to the underside of the part, although this level of sintering is clearly not sufficient to produce an acceptable part strength. This is analogous to the 'bonus' $z$ growth that has been reported in previous SLS research ${ }^{13,14}$.

\section{Effect of IR power level}

Part shrinkage is a well known phenomenon within the Rapid Prototyping and Manufacturing community, and particularly within the Laser Sintering process, where shrinkage of 3-4\% is common for Nylon $12^{15}$. As a result of this, compensation factors are normally used in each direction in an attempt to improve the accuracy of the finished part ${ }^{16}$. 
The observed decrease in the layer thickness produced at the higher power levels in this research is thought to be an indication of greater shrinkage occurring in the $z$ direction, caused by increased densification of the parts as better sintering was achieved. These results are consistent with accepted theory in the SLS process that the shrinkage occurring in a part is largely dependent on the amount of energy inputted into the powder ${ }^{17}$.

\section{Experimental results - part volumes}

In order to identify whether there was, in fact, part shrinkage occurring at higher power levels, the diameters of the parts were measured, and combined with the layer thicknesses obtained via contact methods, to give the overall volume of the finished part. Figure 13 shows the diameters of each sample over the range of power levels tested.

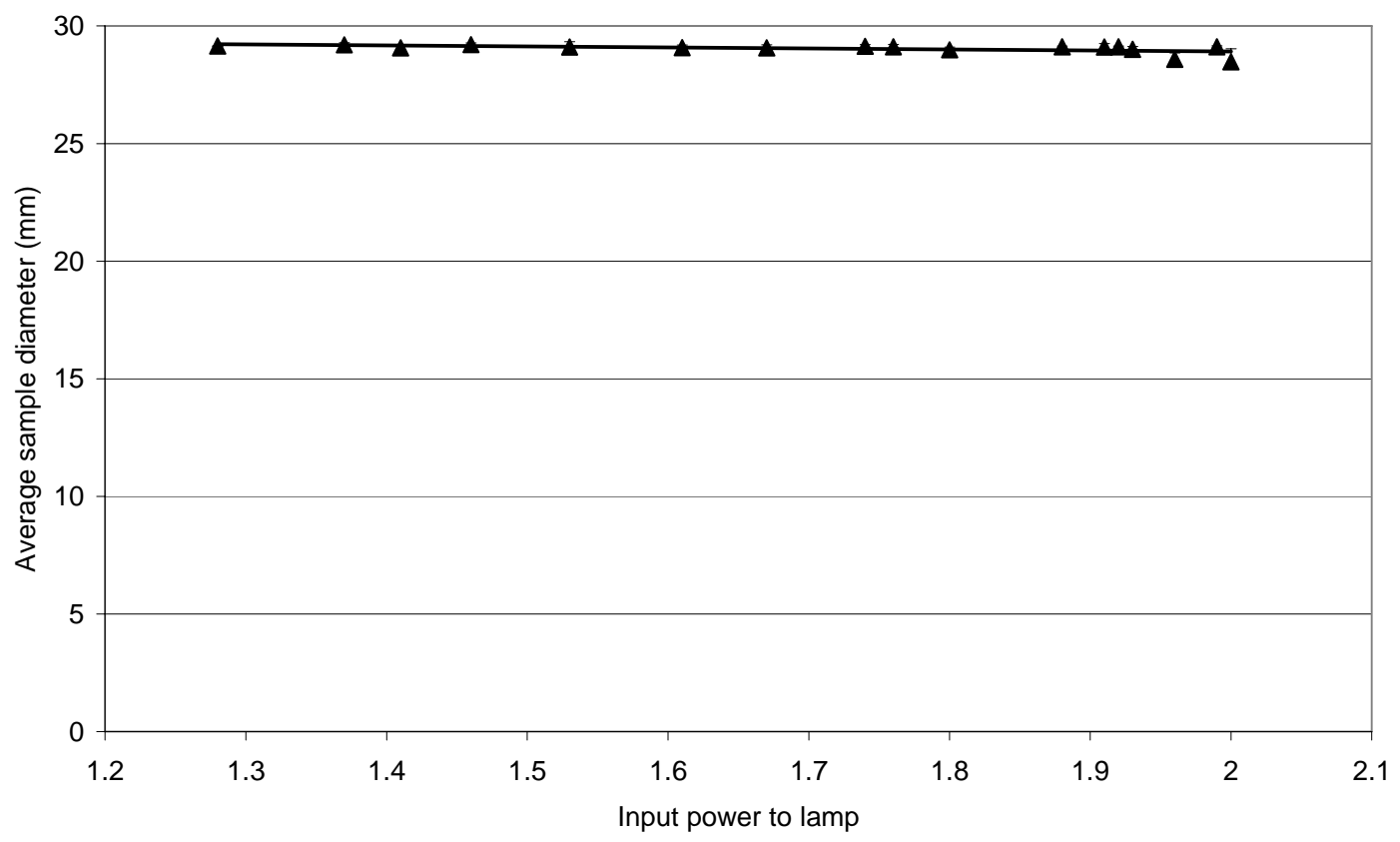

Figure 13 - Average part diameter at each power level

The average of five samples simply printed onto a sheet of paper was taken, and found to be $29.95 \mathrm{~mm}$. It was observed that all sintered samples, although possessing nominal diameters of $30 \mathrm{~mm}$, actually had diameters of less than $29.3 \mathrm{~mm}$, showing that some shrinkage occurs in the $x-y$ plane during the sintering process This suggests that, ultimately, some shrinkage compensation will be required in order to ensure the accuracy of parts produced using HSS. It can also be seen that there was a very small decrease $(\sim 2.5 \%)$ in the average part diameters as the input power to the lamp was increased. These results suggest that the shrinkage in the $x-y$ plane is only marginally affected by the lamp power used.

Figure 14 shows the average volume of the parts produced at the varying lamp input powers. 


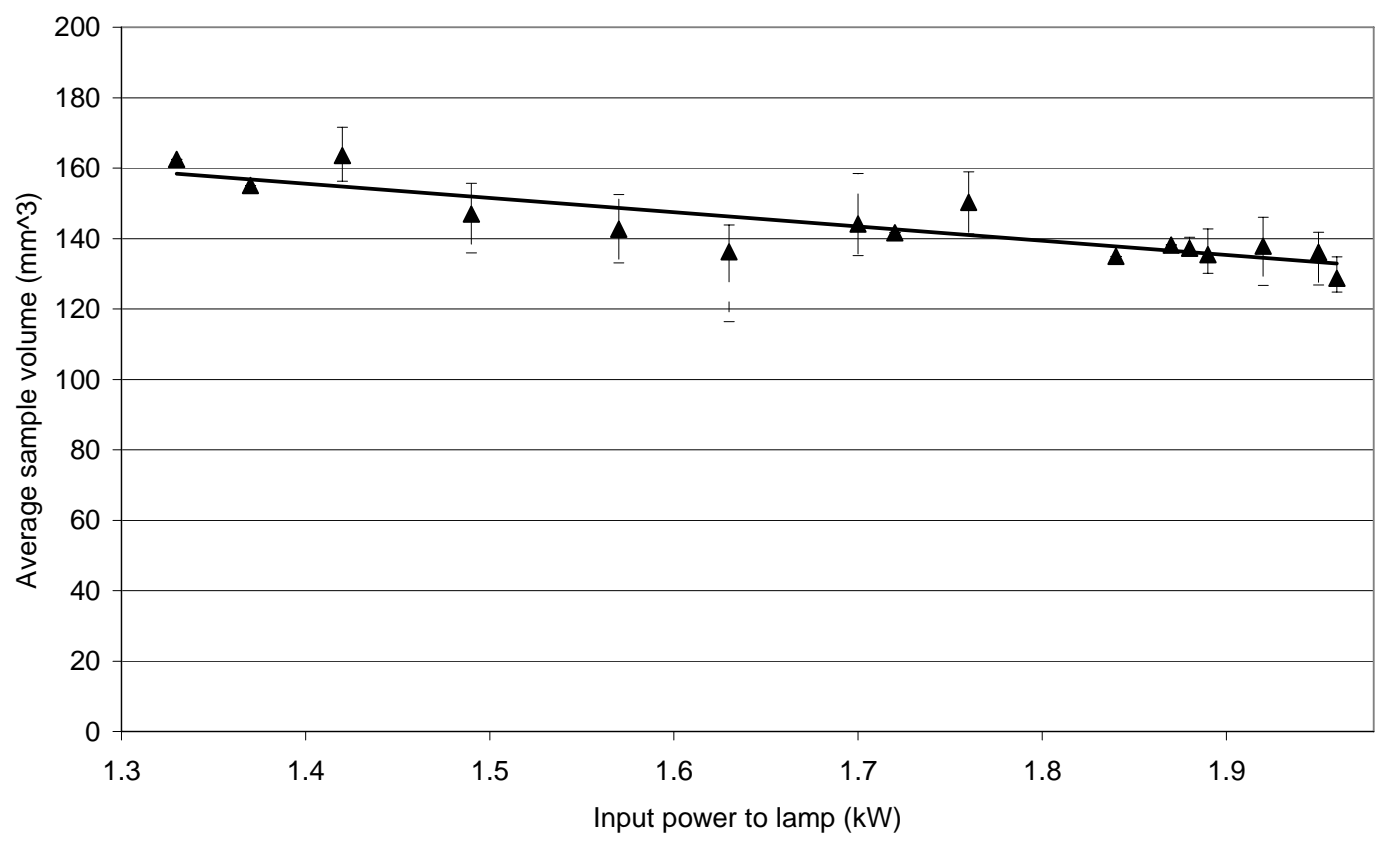

Figure 14 - Average part volume at each power level

In this case there was a pronounced decrease in volume ( $20 \%)$ over the range of values tested. Comparing the layer thickness results with the diameter measurements discussed in the previous paragraphs, it can be seen that the dominant shrinkage effect is in the $z$ direction, becoming more pronounced as the lamp power is increased.

\section{Experimental results - sintering characteristics}

\section{Optical microscopy - sintering characteristics}

Images of the top surface of the test samples were taken using optical microscopy, as discussed previously (see Figure 15). Previous research into the SLS process has shown that higher temperatures lead to increased bonding, and less pores ${ }^{18}$. It was therefore expected that the quality of sintering encountered here would be seen to improve as the infra-red lamp power was increased and more thermal energy was provided to the powder.
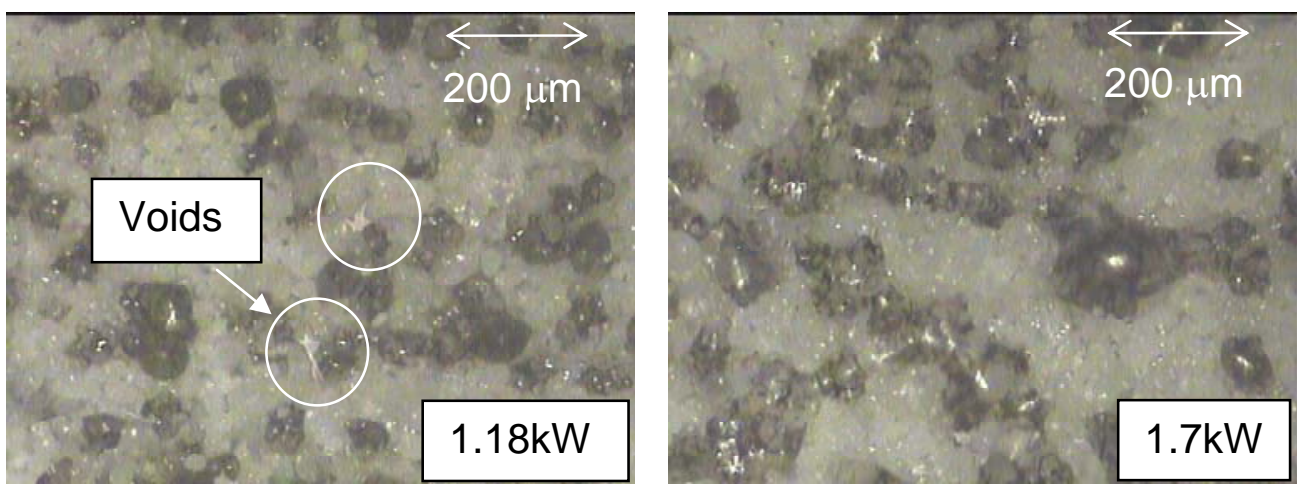


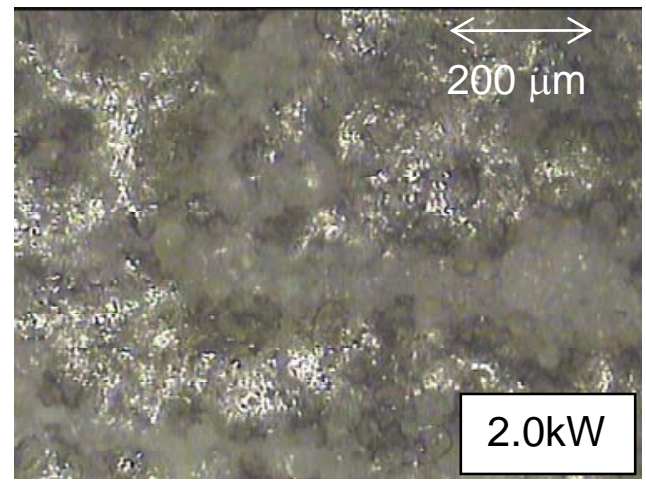

Figure 15 - Top view of parts sintered at different power levels

It can be seen from these figures that the ink delivery, rather than providing overall coverage of the printed area, instead produces discrete droplets on the surface. These individual droplets are therefore responsible for transferring the infra-red radiation from the lamp to the surrounding powder. At the 5.0 power level the presence of a number of voids can easily be observed, where the energy transferred from the RAM droplet is not sufficient to produce a fully sintered part. As the lamp power was increased, a corresponding increase in the level of sintering could also be observed.

\section{Discussion of sintering characteristics}

At the higher power levels it could be observed that the coverage of the RAM was more even than at the lower levels. As the higher amount of energy is input into the powder, this allows the top layer of particles to sinter more rapidly, and therefore to melt to a greater degree, than with the lower power levels. This in turn causes an increase in the apparent surface area of the powder, and therefore in the perceived distribution of the RAM over the surface. This effect could also have major ramifications for the surface finish of an HSS part, as the increased melting will lead to a more uniform and flat surface on the top layer of the part.

As discussed previously, it was originally expected that the layer thickness that could be achieved would increase at higher IR lamp powers. However, the results obtained, showing a slight decrease in the layer thickness at higher levels, coupled with the optical images showing greater sintering on the top surface at higher levels, suggest that the heat transfer process is more effective in the $x-y$ plane than in the $z$ direction. This may partly be due to large areas of overlap between the areas of thermal influence of adjacent droplets of RAM on the $x-y$ surface, as opposed to in the $z$ direction where this will have less of an effect.

Also to be considered is the area of influence of the RAM on heat transfer into the loose powder. At the instant of irradiation, the influence of the RAM in each direction will be the approximately equal, as shown in Figure 16a. However, the thermal energy will initially affect the top surface of the powder, causing sintering to occur. Once sintering has been initiated, necking will occur predominantly within the top layer of powder. It is thought that, as this 
necking begins to occur, the joining of the polymer particles, and the corresponding lessening in the air gaps between them, allows for greater heat transfer in the $x-y$ plane than in the $z$ direction, as shown in Figure 16b.

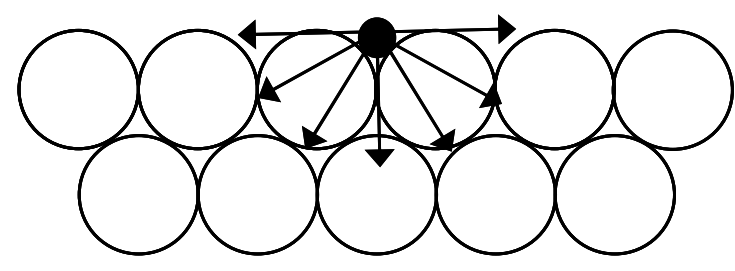

a

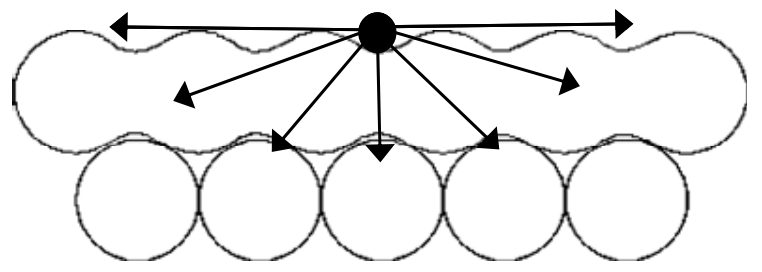

b

Figure 16 - Area of influence of RAM a) at initial instant of radiation b) once sintering has commenced

This would help to explain the existence of a maximum achievable thermal penetration depth within the process. This can also be related to SLS research ${ }^{18}$ which shows that sintering occurs to a lesser degree in the $z$ direction than in the $x$ and $y$ directions, indicating that less thermal energy is transferred in the $z$ direction.

\section{Conclusions}

It has been shown that there is a maximum depth of influence of heat transfer in the $z$ direction. Rather than the expected trend of increased layer thickness at higher power levels, there was in fact a slight decrease. The increase in thermal energy at the higher powers appears from the optical microscopy results to cause a greater degree of sintering at the higher levels, whilst still only providing sufficient thermal penetration to sinter to a similar depth $(\sim 200 \mu \mathrm{m})$. This, coupled with the slight shrinkage associated with the better sintering behaviour, causes a small decrease in the thickness of a single layer.

The penetration depth may be increased when using different RAM or powders, but it can be expected that increasing the lamp power, whilst enhancing the part properties, will not increase the maximum layer thickness that can be sintered for any one combination of materials.

Finally it may be expected that the shrinkage encountered at higher lamp powers may provide a better surface finish at the top of a part, as a result of greater melting and subsequent smoothing of the sintered powder.

\footnotetext{
${ }^{1}$ Wohlers, T., Rapid prototyping Tooling and Manufacture Annual State of the Industry Report, Wohlers Associates, USA, 2006

${ }^{2}$ Chua, C.K., Leong, K.F. and Lim, C.S., Rapid Prototyping, Principles and Applications, World Scientific Publishing Co. Pte. Ltd, Singapore, ISBN 981238-117-1, 2003

${ }^{3}$ Hopkinson, N., Hague, R.M.J. and Dickens, P.M., Rapid Manufacturing and Industrial Revolution for the Digital Age, John Wiley and Sons Ltd, ISBN 13 978-0-470-01613-8
} 
${ }^{4}$ Weaver, T., Made to measure, Engineering magazine, May 2006, pp20-21, ISSN 0013-7782

${ }^{5}$ De Grange, Paradigm shift from Rapid Prototyping to Direct Manufacturing, Proceedings from the SLS User Group meeting, Orlando, Florida, September 2003

${ }^{6}$ Hopkinson, N. and Dickens, P.M., Analysis of Rapid Manufacturing - Using Layer Manufacturing Processes for Production, Proceedings of the Institute of Mechanical Engineers (Part C), Journal of Mechanical Engineering Science, Professional Engineering Publishing Limited, London, UK, Vol 217, Number C1, 2003, pp31-39, ISSN 0954-4062

7 Khoshnevis, B., Asiabanpour, B., Mojdeh, M., Koraishy, B., Palmer, K. and Deng, Z., SIS - A New SFF Method Based on Powder Sintering, Proceedings from the $13^{\text {th }}$ SFF Symposium, Austin, Texas, USA, August, 2002, pp440-447, ISSN 1053-2153

${ }^{8}$ Asiabanpour B., Khoshnevis, B., Palmer, K. and Mojdeh, M., Advancements in the SIS Process, Proceedings from the $14^{\text {th }}$ SFF Symposium, Austin, Texas, August 4-6, 2003, pp 25-38, ISSN 1053-2153

${ }^{9}$ Kumar, A.V., and Dutta, A., Investigation of an electrophotography based rapid prototyping technology, Rapid Prototyping Journal, Volume 9, Number 2, 2003, pp. 95-103, MCB University Press Limited, ISSN 1355-2546

${ }^{10}$ Kumar, A. V. Dutta, A. and Fay, J.E., Electrophotographic printing of part and binder powders, Rapid Prototyping Journal Volume 10, Number 1, 2004, pp. 7-13, Emerald Group Publishing Limited, ISSN 1355-2546

${ }^{11}$ Hopkinson, N. and Erasenthiran, P.E., High Speed Sintering - Early research into a new Rapid Manufacturing process, Proceedings from the 15th SFF Symposium, Austin, Texas, August 2004, pp 312-320

12 Thomas, H.R., Hopkinson, N., and Erasenthiran, P.E., High Speed Sintering - Continuing research into a new Rapid Manufacturing process, Proceedings from the 17th SFF Symposium, Austin, Texas, August 2006 ${ }^{13}$ Sercombe, T.B. and Hopkinson, N., Process Shrinkage and Accuracy during Indirect Laser Sintering of Aluminium, Advanced Engineering Materials, 8(4), April 2006, pp 260-264, ISSN 1438-1656, ${ }^{14} \mathrm{Ho} \mathrm{H.,} \mathrm{Cheung,} \mathrm{W.} \mathrm{and} \mathrm{Gibson,} \mathrm{I.,} \mathrm{Effects} \mathrm{of} \mathrm{graphite} \mathrm{on} \mathrm{the} \mathrm{laser} \mathrm{sintering}$ behaviour of polycarbonate Rapid Prototyping Journal, V 8 pp233 - 242, 2002 ${ }^{15}$ Grimm, T., User's Guide to Rapid Prototyping, Society of Manufacturing Engineers, Dearborn, Michigan, 2004, ISBN 0872636976

16 Jacobs, P., Stereolithography and other RP\&M Technologies, Society of Manufacturing Engineers, Dearborn, Michigan, 1996, ISBN 0781634671

17 Williams, J. and Deckard, C., Advances in modelling the effects of selected parameters on the SLS process, Rapid Prototyping Journal, V 4, N 2, 1998, pp 90-100

${ }^{18}$ Ajoku, K., Saleh, N., Hopkinson, N. Hague, R. and Erasenthiran, P., Investigating mechanical anisotropy and end-of-vector effect in laser-sintered nylon parts, Proc. IMechE Part B: J. Engineering Manufacture, V 220, 2006 